\title{
PROFIL KOMPETENSI LULUSAN SMK NEGERI 1 KALIANGET PROGRAM STUDI MEKANIK OTOMOTIF YANG DIHARAPKAN STAKEHOLDER
}

\author{
Ngadi \\ Prodi Teknik Mekanik Otomotif SMKN 1 Kalianget \\ ngadicuk_unija@gmail.com
}

\begin{abstract}
ABSTRAK
Arah penyelenggaraan pendidikan dan pelatihan di SMK harus mengedepankan aspek efektif, efisien, dan bermutu, yang mengintegrasikan antara kompetensi profesional, kompetensi kepribadian, dan kompetensi kewirausahaan. Keterjalinan dan keterpautan antara penyelenggaraan pendidikan dan pelatihan di SMK dengan kepentingan dan harapan stakeholder, terutama tentang profil kompetensi lulusan yang akan mereka pakai, adalah suatu keniscayaan. Perlu studi yang akurat dan dapat dipertanggungjawabkan tentang preferensi stake holder terhadapkompetensi lulusan SMK, sebagai tenaga kerja tingkat madya yang mereka pakai.Analisis konjoin adalah salah satu metode statistik multivariate, yang biasa digunakan untuk riset pasar, digunakan untuk menentukan preferensi konsumen terhadap suatu produk atau jasa.Hasil studi preferensi diharapkan dapat dijadikan pertimbangan yang masuk akal oleh sekolah (SMK) atau guru pengajar SMK dalam membuat kebijaksanaan manajemen atau pendekatan pembelajarannya, terutama aspek konsentrasi materi serta model pembelajarannya sehingga relevan dengan kebutuhan stake holder
\end{abstract}

\section{Kata kunci: Profil kompetensi, Lulusan SMK, Preferensi, Stake holder, Analisis conjoin}

\section{PENDAHULUAN}

Undang Undang Nomor 20 Tahun

2003 Pasal 18 tentang Sisdiknas menyebutkan, visi Sekolah Menengah Kejuruan (SMK) adalah mewujudkan pendidikan dan pelatihan kejuruan berstandar nasional dan internasional. Menurut Kuswana (2013), terdapat empat tujuan pokok dalam penyelenggaraan pendidikan dan pelatihan di SMK, yaitu: (1) untuk menyiapkan peserta didik agar dapat bekerja, baik secara mandiri maupununtuk mengisi lowongan pekerjaan yang ada di dunia usaha atau industri, sebagai tenaga kerja tingkat menengahsesuai bidang dan program keahlian yang diminati; (2) membekali peserta didik agar mampu memilih karir, ulet, dan gigih dalam berkompetisi, dan mampu mengembangkan sikap profesional dalam bidang keahlian yang diminati; (3) membekali peserta didik ilmu pengetahuan dan teknologi agar mampu mengembangkan diri melalui jenjang pendidikan yang lebih tinggi; dan (4) membekali peserta didik agar mampu berusaha mandiri di masyarakat (Kuswana, 2013).

Paparan di atas menunjukkan, terdapat tiga konsentrasi penting dalam rangka peningkatan mutu kompetensi peserta didik SMK, yaitu: (1) kompetensi keahlian profesional, (2) kompetensi karakter individu profesional, dan (3) kompetensi kewirausahaan yang dibutuhkan di dunia kerja dan perkembangan masyarakat dan dunia kerja. Kompetensi adalah karakteristik peserta didik (lulusan) SMK yang berhubungan dengan kriteria (spesifikasi standar) tertentu yang telah disepakati (Spencer \& Spencer, 1993), meliputi aspek: (1) pengetahuan, (2) keterampilan, dan (3) sikap (Undang-Undang RI No.13 Tahun 2003).

Kompetensi profesional adalah hard skills merupakan surface personality atau yang dapat diamati, yaitu 
kemampuan para lulusan SMK yang dianggap mampu oleh masyarakat atau stake holder (pemangku kepentingan) untuk melaksanakan tugas-tugas di bidang pekerjaan tertentu (Kepmendiknas RI Nomor 045/U tahun 2002) sesuai dengan disiplin keahlian yang dimilikinya. Kompetensi profesional tersebut harus dilandasi oleh ilmu pengetahuan, pengetahuan, dan pengetahuan praktis, yang dapat diukur melalui: (1) penguasaan ilmu pengetahuanyang berbasis sains,yaitu didukung oleh rekam data, observasi dan analisa yang terukur dalam memecahkan masalah, serta (2) penguasaan keterampilan psikomotorik oleh lulusan melakukan pekerjaan menggunakan manual dexterity (tangan dan pikiran) dalam penggunaan metode, bahan, alat dan instrumen yang tepat (sesuai) sehingga mampu menghasilkan produk, jasa, atau unjuk kerja yang dapat dinilai secara kualitatif maupun kuantitatif (Peraturan Presiden RI Nomor 01 tahun 2012; Permendikbud RI Nomor 70 tahun 2013).

Kompetensi karakter individu (profesional) adalah soft skills yang core personality (tidak termati), yaitu afeksi atau sikap yang berhubungan dengan: (1) dalam dirinya sendiri sebagai individu; dan (2) terhadap orang lain lain di lingkungan sekitar kehidupannya sebagai anggota social (Depdikbud, 2012 Modul2). Menurut ABET (Accreditation Board for Engineering and Technology) EC 2000, sebuah lembaga akreditasi internasional, kriteria soft skills yang paling dibutuhkan di dunia kerja saat ini adalah: (1) mampu menjalin hubungan dengan teman yang multidisiplin, (2) bertanggung jawab dan beretika profesional, (3) mampu berkomunikasi secara efektif, (4) memahami pengaruh rekayasa dalam arti luas, (5) mampu menyelesaikan masalah sosial dan global, (6) berkeinginan selalu belajar terusmenerus, (7) paham masalah yang terjadi saat ini (Carter, 2001). Sedangkan menurut Abourjilie (2006), tertuang dalam proyek Student Citizen Act 2001, karakter dibutuhkan individu meliputi kemampuan: (a) berani bertindak karena keyakinan yang benar, (2) mampu menilai dan memilihdengan cara yang tepat, (3) Integritas atau jujur, (4) berperilaku baik, sopan, peduli, bersahabat, dermawan, (5) tekun dan tabah untuk selalu mencoba ketika gagal, (6) menghormati kepentingan orang lain, (7) bertanggung Jawab terhadap tugasnya, dan (9) berdisiplin mengikuti aturan yang berlaku.

Kompetensi kewirausahaan (enterpreunership) adalah berhubungan dengan kemampuan lulusan SMK dalam menciptakan sesuatu dunia usaha yang baru, yang membutuhkan waktu dan pengorbanan, memiliki resiko baik sosial, pendapatan, kepuasan, serta kebebasan pribadi (Peters dan Sheperd, 2008 dalam Jihad, dkk., 2010). Kompetensi ini lebih berfokus pada kemampuan lulusan dalam: (1) berani mengambil resiko, (2) menjalankan usaha sendiri, memanfaatkan peluang-peluang, menciptakan usaha baru, (5) berinovasi dan (6) mandiri dan tidak bergatung pada bantuan pemerintah.

Dunia industri, sebagai stake holder (pemangku kepentingan) pengguna tenaga kerja lulusan SMK sangat berkepentingan terhadap profil mutu lulusan yang benar-benar sesuai dengan kriteria standar yang ditetapkan mereka. Dalam rangka menjalankan tugas pokok dan fungsinya tersebut, SMKN 1 Kalianget Prodi Teknik Mekanik Otomotif (yang selanjutnya dalam penelitian ini disebut SMK saja), sebagai Satuan Pendidikan Menengah Kejuruan harus cerdas dalam mengidentifikasi dan menjembatani antara permintaan profil lulusan yang dihasilkan SMK terhadap kebutuhan yang dikehendaki stake holder. Penyelenggaraan pendidikan dan pelatihan di SMK harus dirancang sedemikian rupa (tersistem) sehingga mampu mengembangkan kompetensi 
lulusan yang memiliki keseimbangan ketiga aspek di atas (profesional, kepribadian, dan kewirausahaan), dengan mengedepankan efektifitas, efisiensi, dan bermutu.Dengan demikian, profil lulusan SMK ke depan benar-benar yang diterima dan dibutuhkan oleh stake holder, namun substansi materi pelajaran tetap mempertimbangkan kebutuhan individu peserta didik.

Pertanyaannya adalah kecenderungan profil kompetensi lulusan SMK seperti apakah yang dikehendaki (diinginkan) stake holder? Apakah setiap segmen stake holder memiliki kecenderungan sama dalam menghendaki profil kompetensi lulusan? Perlu studi pasar menggunakan metode analisis statistik yang tepat dan dapat dipertanggung jawabkan dalam rangka menentukan model yang diinginkan stake holder.Studi preferensi adalah keinginan seseorang (responden) untuk memilih sesuatu yang mereka harapkan sesuai dengan kesenangan dan kepuasan (Astiawati, 2013).Studi preferensi adalah penting, sebab: (1) stake holder sebagai konsumen memiliki penekanan bebeda-beda dalam menilai setiap faktor dan turunannya; (2) stake holder memiliki kepercayaan terhadap kepentingan faktor pada setiap profil lulusan; (3) tingkat kepuasan stake holder terhadap profil lulusan beragam sesuai dengan perbedaan faktor; dan (4) stake holder akan sampai pada sikap terhadap produk yang berbeda melalui prosedur evaluasi (Gundono, 2011). Pada akhirnya, studi preferensi stake holder tersebut dapat digunakan sebagai pertimbangan cerdas oleh SMK (terutama guru pengampu) dalam membuat kebijaksanaan yang tepat tentang profil muatan materi yang akan mereka kembangkan kepada peserta didik di sekolah atau di kelas.

\section{METODE PENELITIAN}

Penelitian ini menggunakan analisis konjoin, yaitu analisis statistic multivariate yang mengadopsi metode riset pasar untuk menentukan preferensi konsumen terhadap suatu produk atau jasa (Ghozali, 2011). Artinya, teknik ini dikembangkan untuk memahami model preferensi atau keinginan stake holder (untuk setiap individu sebagai informan primer) terhadap profil kompetensi para lulusan SMK yang mereka harapkan.

Responden dalam penelitian ini adalah pemilik/pimpinan bengkel otomotif yang berjumlah 30 orang, baik bengkel mobil (Teknik Kendaraan Ringan/TKR) dan bengkel sepeda motor (Teknik Sepeda Motor/TSM) yang ada di Kota Sumenep. Pemilihan responden dengan pertimbangan bahwa mereka adalah yang pihak berkepentingan (stake holder), baik sebagai dunia industri (profesional) sebagai calon pengguna lulusan SMK maupun sebagai mitra sekolah dalam pelaksanaan dual sistem education atau Praktek Kerja Industri (Prakerin) atau penguji eksternal dalam Ujian Kompetensi Kejuruan (vokasional) SMK. Pengumpulan data menggunakan kuisioner, dimana responden diminta memberikan skor terhadap kombinasi stimuli.

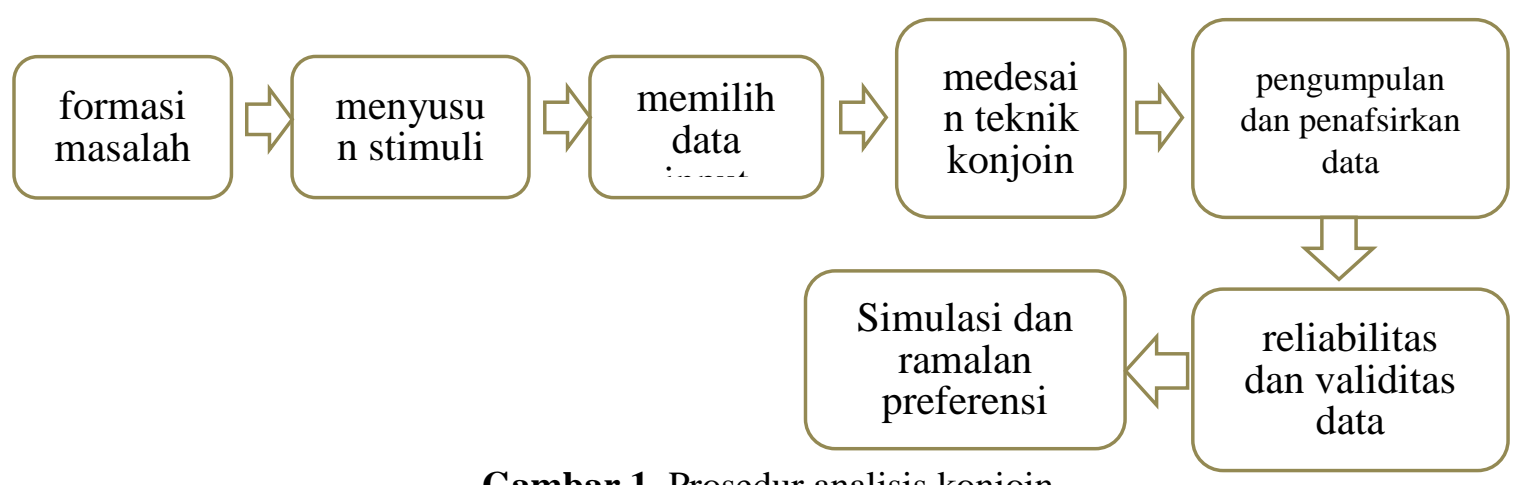

Gambar 1. Prosedur analisis konjoin 
Prosedur analisis konjoin mengacu pada Gundono (2011) yang dimodifikasi (gambar 1), meliputi tahap:

1. Formasi Permasalahan

Tahap menglasifikasi aspek kompetensi lulusan SMK, di mana digolongkan dalam empat faktor (aspek), yaitu: (1) kompetensi profesional, meliputi: (a) menguasai ilmu pengetahuan dan teknologi/ iptek dan (b) terampil bekerja di bidangnya; (2) kompetensi karakter yang berhubungan dengan orang lain/sosial, meliputi: (a) tanggung jawab, dan (b) berperilaku baik; (3). kompetensi kewirausahaan, meliputi: (a) berani mengambil resiko, dan (b) kreatif-inovatif; serta (4). kompetensi karakter yang bersumber dari dalam diri/individual, meliputi: (a) jujur dan integritas, (b) tekun tidak kenal menyerah dan (c) disiplin.

2. Menyusun stimuli

Mengombinasi antara faktor dengan level yang dibentuk dengan cara memilih satu level untuk setiap faktor atau atribut. Metode kombinasi menggunakan pendekatan full-profile-multiple faktor evaluation. Hasil kombinasi antara faktor dengan level dapat dilihat pada tabel 1 .

Tabel 1. Faktor dan level profil lulusan smk yang diharapkan stake holder

\begin{tabular}{|c|c|c|}
\hline No & Faktor (aspek) & vel \\
\hline 1 & (a) Menguasai ilmu Iptek & (b) Terampil bekerja \\
\hline 2 & $\begin{array}{l}\text { Kompetensi karakter profesional(a) Tanggung jawab } \\
\text { sosial }\end{array}$ & (b) Berperlaku baik \\
\hline 3 & Kompetensi kewirausahaan $\quad$ (a) Berani mengambil resiko & (b) Kreatif dan inovatif \\
\hline 4 & $\begin{array}{l}\text { Kompetensi karakter profesional(a) Jujur dan integritas } \\
\text { individual }\end{array}$ & $\begin{array}{ll}\text { (b) tekun } & \text { (c) Dispilin }\end{array}$ \\
\hline
\end{tabular}

3. Memilih data input

Tahap menentukan teknik penyekoran data pada masingmasing profil kompetensi hasil kombinasi antara faktor dengan level. Penelitian ini menggunakan data metrik, di mana responden diminta memberi penilaian dalam bentuk data rating antara nilai 1 (yang sangat tidak diharapkan) sampai dengan 10 (yang sangat ideal sekali).

4. Mendesain analisis konjoin

Yaitu merancang desain eksperimen, yang bergantung pada pendekatan pemberian stimuli dan jenis data yang akan diolah. Mengacu pada pendekatan pemberian stimuli dan jenis data rating, maka desain analisis konjoin dalam penelitian menggunakan regresi-full faktorial.
Langkah-langkah analisis konjoin adalah sebagai berikut.

(a) Membuat variabel dummy dari masing-masing level berdasarkan atribut $(0=$ jika tidak ada dan 1 = jika ada).

(b) Meregresikan dengan variable dummy sebanyak responden

(c) Menentukan nilai utility atau kegunaan, yang mana nilai utility tiap level diperoleh dari nilai konstanta hasil regresi dibagi banyaknya level pada masing-masing faktor.

(d) Menentukan nilai rentangan utility, yaitu selisih nilai utiliy masing-masing faktor, kemudian menjumlah rentang seluruh factor 
Tabel 2. Kombinasi antara level profil lulusan SMK yang diminati stake holder

\begin{tabular}{|c|c|c|c|c|}
\hline No & & Profil Lulusan $\mathbf{S}$ & Yang Diharapkan & \\
\hline 1 & - Menguasai IPTEK & - Berperilaku baik & - Kreatif Inovatif & - Jujur \\
\hline 2 & - Menguasai IPTEK & - Berperilaku baik & - Kreatif Inovatif & - Tekun \\
\hline 3 & - Menguasai IPTEK & - Berperilaku baik & - Kreatif Inovatif & - Disiplin \\
\hline 4 & - Menguasai IPTEK & - Berperilaku baik & - Berani beresiko & - Jujur \\
\hline 5 & - Menguasai IPTEK & - Berperilaku baik & - Berani beresiko & - Tekun \\
\hline 6 & - Menguasai IPTEK & - Berperilaku baik & - Berani beresiko & - Disiplin \\
\hline 7 & - Menguasai IPTEK & - Tanggung jawab & - Kreatif Inovatif & - Jujur \\
\hline 8 & - Menguasai IPTEK & - Tanggung jawab & - Kreatif Inovatif & - Tekun \\
\hline 9 & - Menguasai IPTEK & - Tanggung jawab & - Kreatif Inovatif & - Disiplin \\
\hline 10 & - Menguasai IPTEK & - Tanggung jawab & - Berani beresiko & - Jujur \\
\hline 11 & - Menguasai IPTEK & - Tanggung jawab & - Berani beresiko & - Tekun \\
\hline 12 & - Menguasai IPTEK & - Tanggung jawab & - Berani beresiko & - Disiplin \\
\hline 13 & - Terampil bekerja & - Berperilaku baik & - Kreatif Inovatif & - Jujur \\
\hline 14 & - Terampil bekerja & - Berperilaku baik & - Kreatif Inovatif & - Tekun \\
\hline 15 & - Terampil bekerja & - Berperilaku baik & - Kreatif Inovatif & - Disiplin \\
\hline 16 & - Terampil bekerja & - Berperilaku baik & - Berani beresiko & - Jujur \\
\hline 17 & - Terampil bekerja & - Berperilaku baik & - Berani beresiko & - Tekun \\
\hline 18 & - Terampil bekerja & - Berperilaku baik & - Berani beresiko & - Disiplin \\
\hline 19 & - Terampil bekerja & - Tanggung jawab & - Kreatif Inovatif & - Jujur \\
\hline 20 & - Terampil bekerja & - Tanggung jawab & - Kreatif Inovatif & - Tekun \\
\hline 21 & - Terampil bekerja & - Tanggung jawab & - Kreatif Inovatif & - Disiplin \\
\hline 22 & - Terampil bekerja & - Tanggung jawab & - Berani beresiko & - Jujur \\
\hline 23 & - Terampil bekerja & - Tanggung jawab & - Berani beresiko & - Tekun \\
\hline 24 & - Terampil bekerja & - Tanggung jawab & - Berani beresiko & - Disiplin \\
\hline
\end{tabular}

(d) Menentukan nilai importance (kepentingan relatif), diperoleh dari rentang masing-masing faktor dibagi dengan rentang total. Nilai ini digunakan untuk menghitung nilai agregat (residu) atau rata-rata dari nilai kepentingan relatif, artinya melalui nilai agregat maka dapat ditentukan nilai relatif penting pada profil lulusan

(e) Menentukan nilai stimuli, sebagai dasar menentukan preferensi stake holderdalam menentukan profil lulusan SMK yang paling ideal, yang didapat dari persentase rata-rata seluruh nilai utility dari masing-masing stimuli

Tabel 3. Rating penilaian kombinasi level profil lulusan SMK

\begin{tabular}{c|l}
\hline Nilai & Kriteria \\
\hline 1 & Sangat tidak diharapkan \\
\hline 2 & Tidak diharapkan \\
\hline 3 & Cukup diharapkan \\
\hline 4 & Diharapkan \\
\hline 5 & Sangat diharapkan \\
\hline
\end{tabular}

5. Pengumpulan dan penafsirkan data Pengumpulan data menggunakan kuisioner dilanjutkan dengan penafsiran data melalui beberapa

\begin{tabular}{c|l}
\hline Nilai & Kriteria \\
\hline 6 & Sangat diharapkan sekali \\
\hline 7 & Cukup ideal \\
\hline 8 & Ideal \\
\hline 9 & Sangat ideal \\
\hline 10 & Sangat ideal sekali \\
\hline
\end{tabular}

macam teknik analisis, seperti ANOVA, dummy regression, dan part-worth functions. 
6. Menilai reliabilitas dan validitas data Bertujuan menguji kualitas instrumen, dimana penilaian stimuli pada kuisioner dinyatakan valid jika terdapat kesesuaian antara data yang dikumpulkan dengan data yang sesungguhnya, dan dinyatakan reliabel jika mendapatkan hasil yang relatif sama apabila dilakukan penelitian berulang.Uji validitas dan reliabilitas pada penelitian ini menggunakan bantuan software SPSS.

Pengambilan keputusan uji validitas adalah: jika $r$ (korelasi) hasil perhitungan lebih dari $\mathrm{r}$ (korelasi) tabel, maka stimuli dinyatakan valid, dan sebaliknya. Sedangkan, pengambilan keputusan uji realibilitas adalah jika $\mathrm{r}$ Alpha Cronbach lebih dari $\mathrm{r}$ (korelasi) tabel, maka stimuli dinyatakan reliabel.Pada penelitian ini menggunakan $d f=29$ dan $\alpha=5 \%$, maka nilai $r$ tabel yang bersesuaian adalah 0,3 .

7. Melakukan simulasi dan meramalkan prefenrensi

Yaitu meramalkan preferensi stake holder terhadap profil lulusan SMK.

\section{HASIL DAN PEMBAHASAN}

1. Deskripsi Responden/Stake holder

Stake holder adalah pemilik/ pimpinan bengkel berjumlah 30 orang/perusahaan, yang terdiri Bengkel Mobil atau Teknik Kendaraan Ringan (TKR) sebanyak 13 orang, dan Bengkel Sepeda Motor atau Teknik Sepeda Motor (TSM) sebanyak 17 orang. Sedangkan berdasarkan klasifikasi kelas perusahaan, mereka terdiri dari: (a) Bengkel Nonformal, yaitu bengkel yang dikelola secara sendiri oleh pemiliknya serta tidak memiliki aturan operasional standar baku yang berjumlah 21 buah; dan (b) Bengkel Formal, yaitu bengkel authorized oleh Asosiasi Tunggal Pemegang Merek (ATPM), memiliki aturan operasional standar baku berjumlah yang 9 buah.

2. Validitas dan Reabilitas

Hasil uji validitas penilaian dari 24 stimuli, nilai semua stimuli adalah lebih dari 0,3. Korelasi terbesar adalah pada stimulasi nomor 5 , yaitu 0,873 , sedangkan korelasi terendah adalah stimuli nomor 15 yaitu 0,308 pada. Hal ini dapat diinterpretasikan bahwa semua penilaian terhadap stimuli adalah valid. Dari hasil perhitungan nilai Alpha Cronbach adalah 0,947, dimana nilai ini lebih dari nilai korelasi tabel. Hal ini menunjukkan bahwa instrumen pada penelitian ini adalah reliabel. Karena semua stimuli valid dan reliabel, maka data hasil dari instrumen pada penelitian ini layak dilanjutkan untuk dianalisis.

3. Hasil Analisis Konjoin

(a) Preferensi stake holder terhadap stimuli

Hasil perhitungan nilai agregat utility dan persentasenya menggunakan software SPSS dan excel (Tabel 4), bahwa penilaian stake holder terhadap stimuli (kombinasi nilai-nilai profil lulusan) yang paling ideal menurut merekaadalah stimuli nomor 19, yaitu: terampil bekerja, tanggung jawab, kreatif dan inovatif dan jujur dengan nilai agregat 0,7933 .

Tabel 4. Preferensi stake holder terhadap profil lulusan SMK

\begin{tabular}{clc}
\hline No. Stimuli & \multicolumn{1}{c}{ Nilai Agregat } & Rangking preferensi \\
\hline 1 & 0.024066667 & 13 \\
\hline 2 & -0.54056667 & 23 \\
\hline 3 & -0.10835 & 16 \\
\hline
\end{tabular}




\begin{tabular}{|c|c|c|}
\hline No. Stimuli & Nilai Agregat & Rangking preferensi \\
\hline 4 & -0.2287 & 18 \\
\hline 5 & -0.79333333 & 24 \\
\hline 6 & -0.36111667 & 20 \\
\hline 7 & 0.351766667 & 6 \\
\hline 8 & -0.21286667 & 17 \\
\hline 9 & 0.21935 & 9 \\
\hline 10 & 0.099 & 11 \\
\hline 11 & -0.46563333 & 21 \\
\hline 12 & -0.46563333 & 22 \\
\hline 13 & 0.465633333 & 4 \\
\hline 14 & -0.099 & 15 \\
\hline 15 & 0.333216667 & 7 \\
\hline 16 & 0.212866667 & 10 \\
\hline 17 & -0.35176667 & 19 \\
\hline 18 & 0.08045 & 12 \\
\hline 19 & 0.793333333 & 1 \\
\hline 20 & 0.2287 & 8 \\
\hline 21 & 0.660916667 & 2 \\
\hline 22 & 0.540566667 & 3 \\
\hline 23 & -0.02406667 & 14 \\
\hline 24 & 0.40815 & 5 \\
\hline
\end{tabular}

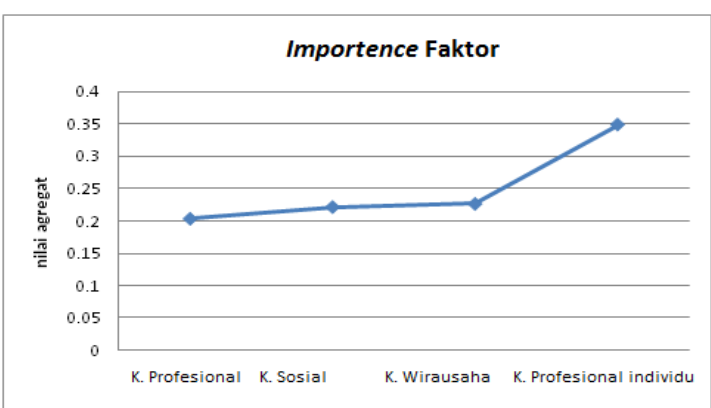

Sedangkan, perbandingan hasil importance (kepentingan relatif) faktor dalam menentukan preferensi stake holder terhadap profil lulusan SMK yang ideal (Gambar2), bahwa faktor yang dianggap paling penting dalam mengukur profil lulusan SMK yang sangat ideal menurut stake holder secara berturut-turut adalah: (1) kompetensi karakter individu; (2) kompetensi kewirausahaaan; (3) kompetensi karakter sosial; dan yang terakhir (4) kompetensi profesional.
Gambar 2. Importance (nilai kepentingan) faktor 


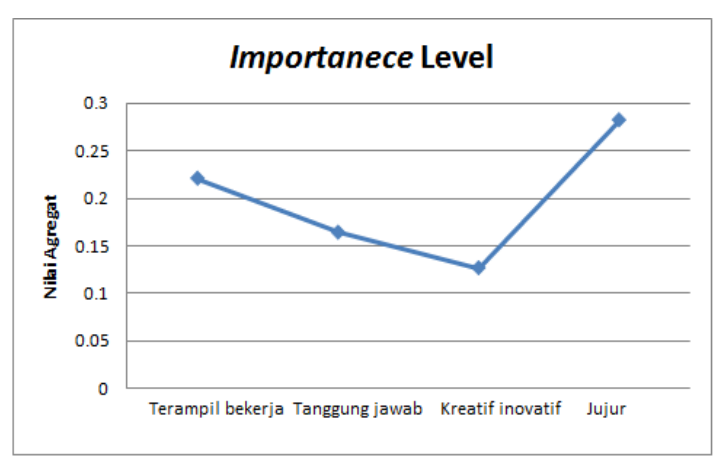

(b) Segmentasi Preferensi Stake holder Berdasarkan Jenis Perusahaan

Hasil preferensi segmentasi stake holder terhadap profil lulusan SMK ideal ditinjau dari jenis perusahaan (Tabel 5) menunjukkan, stake holder dari Bengkel Sepeda Motor (TSM) menganggap lulusan SMK yang ideal adalah stimuli nomor 21, yaitu: terampil bekerja, tanggung jawab, kreatif inovatif dan disiplin, dimana memiliki nilai agregat paling tinggi yaitu 0.7867. Sedangkan, stake holder
Gambar 3. Importance (nilai kepentingan) level

Tabel 5. Preferensi stake holder berdasarkan jenis perusahaan

\begin{tabular}{c|c|c|c|c}
\hline \multirow{2}{*}{ No. Stimuli } & \multicolumn{2}{|c|}{ Bengkel Sepeda Motor (TSM) } & \multicolumn{2}{c}{ Bengkel Mobil (TKR) } \\
\cline { 2 - 5 } & Nilai Agregat & Urutan & Nilai Agregat & Urutan \\
\hline 1 & -0.3028 & 20 & 0.4515 & 7 \\
\hline 3 & -0.4374 & 21 & -0.6755 & 14 \\
\hline 4 & -0.2230 & 17 & 0.0416 & 11 \\
\hline 5 & -0.5724 & 23 & 0.2207 & 24 \\
\hline 6 & -0.7069 & 24 & -0.9063 & 15 \\
\hline 7 & -0.4926 & 22 & -0.1892 & 4 \\
\hline 8 & 0.1579 & 10 & 0.6052 & 19 \\
\hline 9 & 0.0234 & 13 & -0.5218 & 12 \\
\hline 10 & 0.2377 & 9 & 0.1953 & 8 \\
\hline 11 & -0.1116 & 15 & 0.3745 & 22 \\
\hline 12 & -0.2462 & 18 & -0.7525 & 23 \\
\hline 13 & -0.2462 & 19 & -0.7525 & 2 \\
\hline 14 & 0.2462 & 8 & 0.7525 & 17 \\
\hline 15 & 0.1116 & 11 & -0.3745 & 9 \\
\hline 16 & 0.3260 & 6 & 0.3427 & 5 \\
\hline
\end{tabular}




\begin{tabular}{c|c|c|c|c}
\hline \multirow{2}{*}{ No. Stimuli } & \multicolumn{2}{|c|}{ Bengkel Sepeda Motor (TSM) } & \multicolumn{2}{c}{ Bengkel Mobil (TKR) } \\
\cline { 2 - 5 } & Nilai Agregat & Urutan & Nilai Agregat & Urutan \\
\hline 17 & -0.1579 & 16 & -0.6052 & 20 \\
\hline 18 & 0.0564 & 12 & 0.1119 & 13 \\
\hline 19 & 0.7069 & 2 & 0.9063 & 1 \\
\hline 20 & 0.5724 & 3 & -0.2207 & 16 \\
\hline 21 & 0.7867 & 1 & 0.4964 & 6 \\
\hline 22 & 0.4374 & 5 & 0.6755 & 3 \\
\hline 23 & 0.3028 & 7 & -0.4515 & 18 \\
\hline 24 & 0.5171 & 4 & 0.2657 & 10 \\
\hline
\end{tabular}

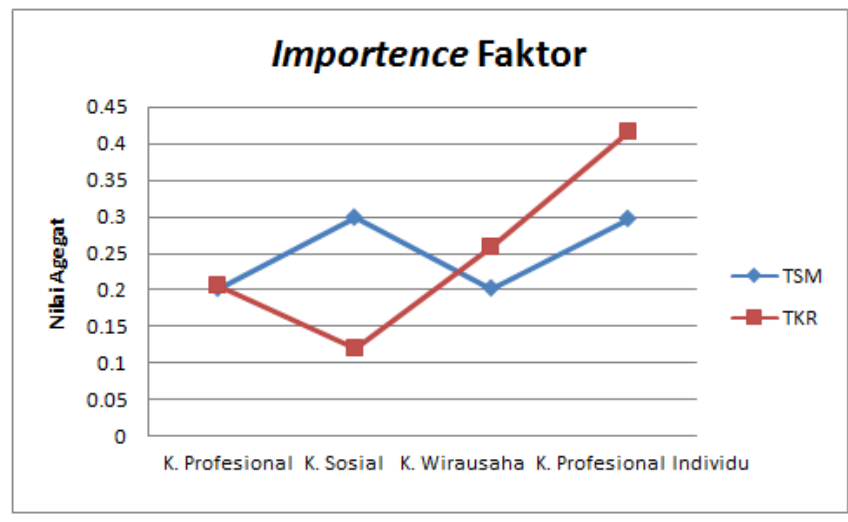

Sementara itu, perbandingan hasil importance (kepentingan relatif) faktor dalam menentukan preferensi stake holder berdasarkan jenis perusahaan terhadap profil lulusan SMK yang ideal (Gambar 4) menunjukkan, faktor yang paling dianggap penting dalam mengukur profil lulusan SMK yang paling ideal menurut stake holder Bengkel Sepeda Motor (TSM), secara berturutturut adalah: (1) kompetensi karakter profesional individu; (2) kompetensi karakter profesional
Gambar 4. Importance (nilai kepentingan) faktor berdasarkan Jenis Perusahaan
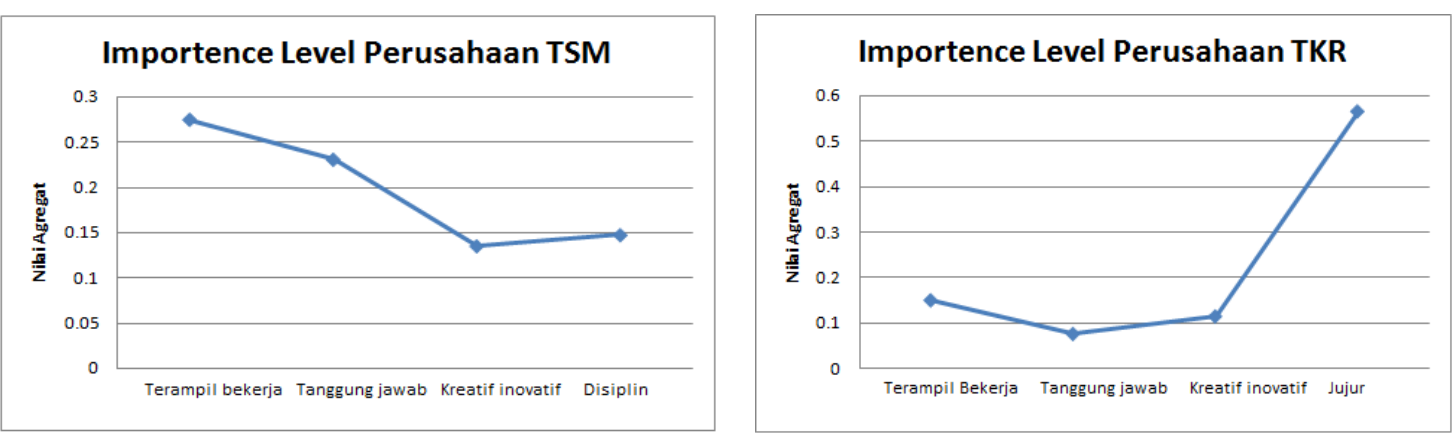
Gambar 5.Importance (nilai kepentingan) level jenis perusahaan (a) TSM dan (b) TKR

Perbandingan dari hasil

importance (kepentingan relatif)

level dalam menentukan

preferensi stake holder dengan jenis Bengkel Sepeda Motor (TSM) terhadap profil lulusan SMK yang ideal (Gambar 5.a) menunjukkan bahwa level yang paling dianggap penting dalam mengukur profil lulusan SMK ideal menurut stake holder dari Bengkel Sepeda Motor (TSM) adalah: (1) terampil bekerja, selanjutnya disusul (2) tanggung jawab; (3) displin; dan yang terakhir adalah (4) kreatif inovatif.

Sedangkan perbandingan hasil importance (kepentingan relatif) leveldalam menentukan preferensi stake holder Bengkel Mobil (TKR) terhadap profil lulusan SMK (Gambar 5.b), bahwa level yang paling dianggap penting dalam mengukur profil lulusan SMK ideal menurut stake holder dari perusahaan yang berjenis TKR adalah: (1) jujur, disusul (2) terampil bekerja, (3) kreatif inovatif dan yang terakhir adalah (4) tanggung jawab.

(c) Segmentasi Preferensi Stake holder Berdasarkan Kelas Perusahaan

Hasil preferensi segmentasi stake holder terhadap profil lulusan SMK ideal ditinjau dari kelas perusahaan dapat dilihat pada Tabel 6. Bahwa stake holder dari Bengkel Nonformal menganggap lulusan SMK yang ideal adalah stimuli nomor 21, yaitu: terampil bekerja, tanggung jawab, kreatif inovatif dan disiplin, di mana memiliki nilai agregat tertinggi 0.7497. Sedangkan stake holder dari Bengkel Formal menganggap lulusan SMK yang ideal adalah stimuli nomor 19, yaitu profil lulusan yang terampil bekerja, tanggung jawab, kreatif inovatif dan jujur, dengan nilai agregat tertinggi 0,9574. Perbedaan kedua stake holder hanya pada faktor kompetensi profesional individu, yaitu Bengkel Nonformal menginginkan disiplin, sementara Bengkel Formal menginginkan sifat jujur.

Perbandingan dari hasil importance (kepentingan relatif) faktor dalam menentukan preferensi stake holder berdasarkan kelas perusahaan terhadap profil lulusan SMK yang ideal (Gambar 6), bahwa faktor yang paling dianggap penting dalam mengukur profil lulusan SMK ideal menurut stake holder dari Bengkel Formal (Authorized/ ATPM) adalah: (1) kompetensi karakter profesional individu, kemudian disusul (2) kompetensi karakter sosial; (3) kompetensi profesional; dan (4) kompetensi wirausaha. Sementara itu, stake holder dari Bengkel Nonformal menganggap faktor yang paling penting untuk mengukur profil lulusan SMK yang ideal adalah: (1) kompetensi kewirausahaan, disusul (2) kompetensi karakter profesional individu; kompetensi karakter sosial; dan yang terakhir adalah kompetensi profesional.

Tabel 6. Preferensi stake holder berdasarkan kelas perusahaan

\begin{tabular}{ccccc}
\hline \multirow{2}{*}{ Stimuli } & \multicolumn{2}{c}{ Formal (ATPM) } & \multicolumn{2}{c}{ Nonformal (mandiri) } \\
\cline { 2 - 5 } & Nilai Agregat & Urutan & Nilai Agregat & Urutan \\
\hline 1 & 0.2723 & 8 & -0.0823 & 16 \\
\hline 2 & -0.7722 & 23 & -0.4413 & 23 \\
\hline
\end{tabular}




\begin{tabular}{|c|c|c|c|c|}
\hline \multirow{2}{*}{ Stimuli } & \multicolumn{2}{|c|}{ Formal (ATPM) } & \multicolumn{2}{|c|}{ Nonformal (mandiri) } \\
\hline & Nilai Agregat & Urutan & Nilai Agregat & Urutan \\
\hline 3 & -0.2314 & 15 & -0.0556 & 15 \\
\hline 4 & 0.0871 & 12 & -0.3640 & 20 \\
\hline 5 & -0.9574 & 24 & -0.7230 & 24 \\
\hline 6 & -0.4166 & 17 & -0.3373 & 19 \\
\hline 7 & 0.6241 & 3 & 0.2350 & 9 \\
\hline 8 & -0.4204 & 18 & -0.1239 & 17 \\
\hline 9 & 0.1204 & 10 & 0.2618 & 8 \\
\hline 10 & 0.4389 & 6 & -0.0467 & 14 \\
\hline 11 & -0.6057 & 20 & -0.4056 & 21 \\
\hline 12 & -0.6057 & 21 & -0.4056 & 22 \\
\hline 13 & 0.6057 & 4 & 0.4056 & 6 \\
\hline 14 & -0.4389 & 19 & 0.0467 & 13 \\
\hline 15 & 0.1019 & 11 & 0.4323 & 5 \\
\hline 16 & 0.4204 & 7 & 0.1239 & 11 \\
\hline 17 & -0.6241 & 22 & -0.2350 & 18 \\
\hline 18 & -0.0833 & 13 & 0.1506 & 10 \\
\hline 19 & 0.9574 & 1 & 0.7230 & 2 \\
\hline 20 & -0.0871 & 14 & 0.3640 & 7 \\
\hline 21 & 0.4537 & 5 & 0.7497 & 1 \\
\hline 22 & 0.7722 & 2 & 0.4413 & 4 \\
\hline 23 & -0.2723 & 16 & 0.0823 & 12 \\
\hline 24 & 0.2685 & 9 & 0.4680 & 3 \\
\hline
\end{tabular}

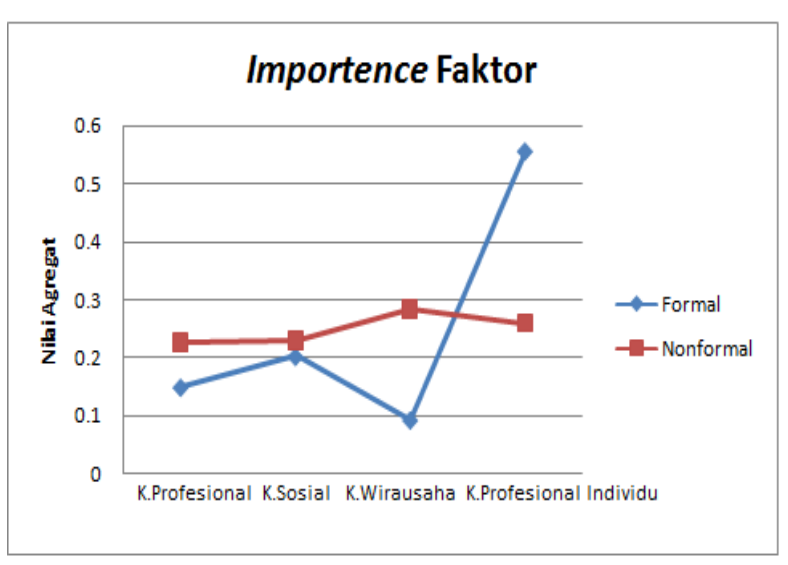

Perbandingan hasil importance (kepentingan relatif) level dalam menentukan preferensi stake holder dengan kelas perusahaan formal terhadap profil lulusan SMK (Gambar 7.a) menunjukkan bahwa level yang paling dianggap
Gambar 6. Importance (nilai kepentingan) faktor berdasarkan Kelas Perusahaan 

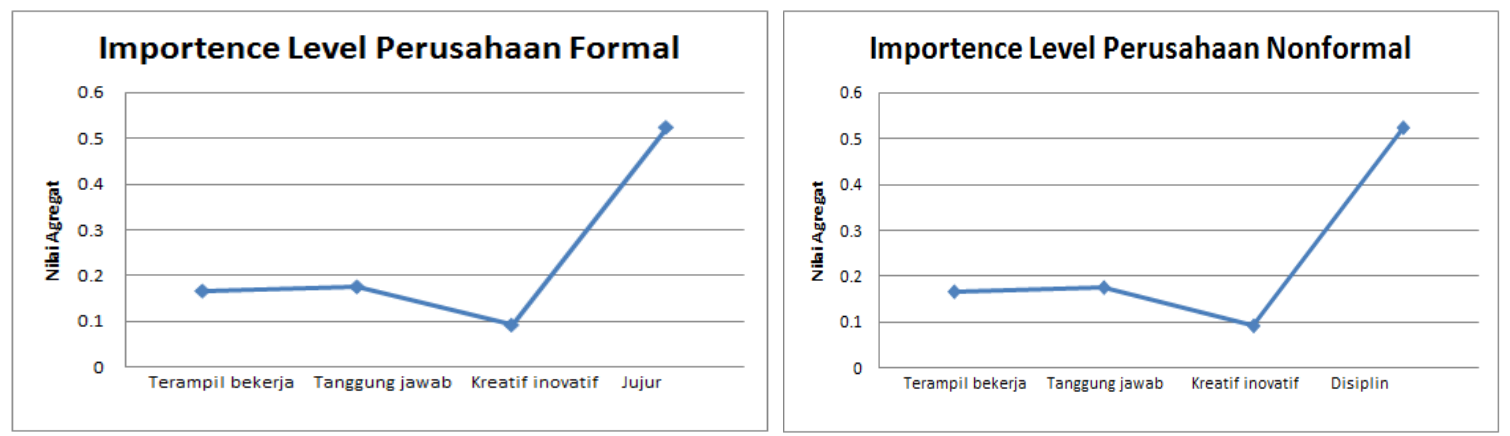

Gambar 7. Importance (nilai kepentingan) level Perusahaan: (a) Formal; (b) Nonformal

Perbandingan dari hasil importance (kepentingan relatif) level dalam menentukan preferensi stake holder dengan kelas Bengkel Nonformal terhadap profil lulusan SMK yang ideal (Gambar 7.b) menunjukkan level yang paling dianggap penting dalam mengukur profil lulusan SMK ideal menurut stake holder dari Bengkel Nonformal adalah: (1) disiplin; disusul (2) tanggung jawab; (3) terampil bekerja; dan yang terakhir adalah (4) kreatif inovatif.

4. Pembahasan

Hasil analisis konjoin menunjukkan, preferensi stake holder terhadap profil kompetensi lulusan SMKN 1 Kalianget yang ideal menurut mereka adalah lulusan yang terampil bekerja, bertanggung jawab, kreatif-inovatif, dan jujur. Stake holder lebih menginginkan kompetensi karakter profesional individualdaripada kompetensikompetensi yang lainnya (yaitu sifat yang berhubungan dari dalam dirinya), terutama kompetensi tentang kejujuran (integritas).

Hasil segmentasi preferensi Stake holder berdasarkan jenis perusahaan, stake holder dari Bengkel Sepeda Motor (TSM) dan Bengkel Mobil (TKR) lebih berkeinginan profil lulusan yang terampil bekerja. Namun, mereka sepakat bahwa kompetensi kompetensi karakter profesional individu lebih penting daripada kompetensi lainnya. Perbedaannya adalah stake holder TSM lebih mengedepankan lulusan yang disiplin, sementara stake holder TKR menginginkan sifat jujur. Perbedaan karakter tersebut sangat dipengaruhi oleh jenis pekerjaan, di mana pekerja TSM bekerja dengan pola one man one machine yang membutuhkan kerja individual, sedangkan pekerja TKR menggunakan kerja kelompok yang berhubungan dengan keterampilan sosial (Santrock, 2010)

Segmentasi Preferensi Stake holder berdasarkan kelas perusahaan, stake holder dari Bengkel Formal dan Bengkel Nonformal lebih berminat pada lulusan yang terampil bekerja daripada aspek lainnya. Perbedaan kedua stake holder hanya pada faktor kompetensi karakter profesional individual, di mana Bengkel Nonformal menginginkan disiplin, sementara Bengkel Formal menginginkan sifat jujur faktor yang paling dianggap penting dalam mengukur profil lulusan SMK yang ideal menurut stake holder dari Bengkel Formal (Authorized/ATPM) adalah kompetensi karakter professional individual, sedangkan stake holder dari Bengkel Nonformal menganggap faktor lebih mementingkan kompetensi kewira- 
usahaan. Fenomena ini terjadi karena Bengkel Nonformal memiliki fasilitas terbatas serta jenis pekerjaan berhadapan dengan berbagai merek, sehingga lebih mementingkan lulusan yang kreatif-inovatif.

Mengacu pada pola preferensi stake holder di atas (agar profil kompetensi lulusan SMK sesuai dengan preferensi stake holder), maka pola pembelajaran di SMK hendaknya mengedepankan pendidikan karakter yang berhubungan dalam diri siswa (individual) daripada kompetensi yang lain (profesional dan kewirausahaan), terutama pada pembelajaran kejujuran dan kedisiplinan. Untuk sukses bekerja, modal kepandaian profesional saja tidak cukup. Keberhasilan seseorang sangat ditentukan oleh sederet potensi-potensi yang terkait dengan karakter (Goleman dalam Santrock, 2010).

\section{SIMPULAN DAN REKOMENDASI}

1. Simpulan

(a) Preferensi stake holder terhadap profil kompetensi lulusan SMKN 1 Kalianget yang ideal menurut mereka adalah lulusan: yang terampil bekerja, bertanggung jawab, kreatif-inovatif, dan jujur.

(b) Stake holder lebih menginginkan kompetensi karakter profesional individual daripada kompetensikompetensi yang lainnya, terutama kompetensi tentang kejujuran (integritas).

(c) Stake holder dari Bengkel Sepeda Motor (TSM) dan Bengkel Mobil (TKR) sama-sama lebih mementingkan kompetensi kompetensi karakter profesional individu lebih penting daripada kompetensi lainnya, namun stake holder TSM lebih mengedepankan lulusan yang disiplin, sementara stake holder TKR menginginkan sifat jujur.

(d) Stake holder dari Bengkel Nonformal dan Bengkel Formal (Authorized/ATPM) lebih berminat pada lulusan yang terampil bekerja daripada aspek lainnya, namun Bengkel Nonformal lebih menginginkan disiplin, sementara Bengkel Formal menginginkan sifat jujur.

\section{Rekomendasi}

(a) Stake holder dalam penelitian adalah pemilik/pimpinan bengkel otomotif di Kota Sumenep, sehingga perlu dikembangkan menggunakan stake holderyang berasal dari dunia industri yang lebih luas.

(b) Analisis konjoin dalam penelitian hanya menggunakan 4 faktor dan 9 Level sehingga belum menggali kombinasi antara level profil kompetensi lulusan SMK yang lebih luas (detail), sehingga perlu penelitian konjoin lanjutan yang menggunakan jumlah faktor dan level lebih besar.

(c) Hasil analisis conjoin stake holder menunjukkan perlu penekanan pada pola, tujuan, dan materi pembelajaran di SMK yang lebih menekankan pada pendidikan karakter professional individual, terutama pada aspek kejujuran. Perlu penelitian pengembangan model pembelajaran berpendekatan pendidikan karakter profesional individual di SMK.

\section{DAFTAR PUSTAKA}

---------. (2003). Undang Undang RI Nomor 20 Tahun 2003 Pasal 18 tentang Sistem Pendidik Nasional.

---------. (2003). Undang-Undang RI Nomor 13 Tahun 2003 tentang Ketenagakerjaan.

(2005). Peraturan Pemerintah RI Nomor 19 Tahun 2005 
tentang Standar Nasional Pendidikan

(2006). Permendiknas RI Nomor 22 Tahun 2006 tentang Standar Isi Pendidikan Dasar dan Menengah

(2012). Peraturan Presiden RI Nomor 01 tahun 2012 tentang Protokol untuk Melaksanakan Komitmen Paket Ketujuh dalam Persetujuan Kerangka Kerja ASEAN di Bidang Jasa. (2012). Peraturan Presiden RI Nomor 8 Tahun 2012 tentang Kerangka Kualifikasi Nasional Indonesia

(2013). Permendikbud RI nomor 70 tahun 2013 tentang Kerangka Dasar dan Struktur Kurikulum Sekolah Menengah Kejuruan/Madrasah Aliyah Kejuruan

(2002). Kepmendiknas RI Nomor 045/U Tahun 2002 tentang Kurikulum Inti Pendidikan Tinggi

Abourjilie, Charlie, et. al. (2006).Character

Education:Informational

Handbook \& Guide II. Nort Carolina: State Board of Educationan Dept. of Public Instruction Middle Grades Divission

Astiwati, Rina. (2013). "Kajian analisis conjoin dalam menelaah preferensi peserta didik terhadap suasana belajar IPA di SMPN 2 Kalianget." Skripsi Prodi Pendidikan Sains FKIP Universitas Wiraraja Sumenep.

Carter, (2001). Miichael, et. al. EC 2000. Criterion 2:A Procedure For Creating, Assessing, And Documenting Program Educational Objectives.in Proceedings of the 2001 American Society for Engineering Education Annual
Conference \& Exposition. New York: American Society for Engineering Education

Ghozali, Imam. (2011). Aplikasi Analisis Multvariat Dengan Program SPSS. Semarang: Universitas Diponegoro.

Gudono. (2011). Analisis Data Multivariat. Yogjakarta: BPFEYokyakarta.

Jihad, Asep; Rawi, M. Muchlas; dan Komarudin, Noer. (2010).

Pendidikan Karakter: Teori dan Aplikasi. Jakarta: Direktorat Pendidikan Dasar dan Menengah Kementrian Pendidikan Nasional Kuswana, Wowo Sunaryo. (2013). Filsafat Pendidikan Teknologi, Vokasi dan Kejuruan. Bandung: Alfabeta

Santrock, W, John. (2010). Psikologi Pendididkan.Jakarta: Kencana.

Slavin, Robert. (1995). Educational Psychology:Theoryand Practice. Masecussets: Merril and Glencoe Pub. Co.

Spencer, lyle M\&Signe M. Spencer. (1993). Competence Work: Modal for Superior Performance. Toronto: John Willey and Sons Inc. 